At 3 p.x. I found her much improved; she had very much regained the power of speech, and could move the right arm; but the hand continued in a state of clonic spasm when awake, and was swollen and painful, re. quiring warm fomentations. She continued throughout the day to take the same kinds of nourishment, sleeping quietly in the intervals. She had a good night, but became restless at about 7 A.M. (Monday, 21st). Nevertheless, her mental powers were much improved, and there was less paralysis of the arm. I gave her another opiate enema, but it returned almost immediately. (She had not had one since 4 P.s. on Saturday.) She complained of the soreness of the blister, which was therefore dressed with cerate, instead of mercurial ointment. Pulse 80 . She said she was hungry, and ate some bread and butter. She could put her tongue out quite straight, and speak almost naturally. Having had no relief from the bowels since Friday, we ordered a soap and water and castor oil enema to be administered after she had had another sleep; and I left her at 9 A.sr.

On T'uesday, the 22nd, I heard she had passed another sery good night, and continued to improve. After this, I received accounts varying in importance from day to day ; sometimes of improvement; at other times, of re. turn of headache; albumen was once more discovered in the urine; less urine was passed; the mind occasionally became restless; and the impression on the part of her own medical attendant, that the symptoms could only be satisfactorily explained by uræmic intoxication, was strengthened.

I was summoned again on Saturday, the 26th, at 2.30 A.Mr. She was then weak and exhausted, but clear about the head, and not, as far as I could see, materially worse. Her bowels did not act well; and she now refused the use of enemata. We ordered her a potash and rhubarb draught, and some citrate of quinine and iron. Subse. quently to this, Dr. —— applied a blister behind each ear, on account of the head becoming more painful ; and some morphia was given at night with good effect. On testing the urine a day or two afterwards, no albumen could be found, and the specific gravity was natural. One day, after a very long sleep, she awoke much more cheerful, and expressed herself as feeling decidedly better. The quinine had been discontinued, and she took instead a mixture containing solution of acetate of ammonia and tincture of sesquichloride of iron, which agreed well. She could use her right hand a little; sit up in bed; take food well; and seemed steadily improving.

On May 8th, I received a report that all was going on favourably; that șe had been in her drawing-room, sat in an easy chair, and helped herself to her dinner. Her mind was cheerful and collected. Pulse still feeble. The hand was gradually regaining power; bowels regular; urine healthy. The vision of the left eye was imperfect as to distant objects, which are seen double; but when they were brought near, she could see them distinctly.

On May 17 th, I found her reclining on a sofa in her drawing-room, cheerful, free from pain, with appetite and strength returning, and paralysis gone. She still, however, complained of seeing double at a distance when using both eyes, although, with either eye alone, she saw a single object; proving that her double vision depended upon a want of consent between the two eyes on directing them to an object.

June 3rd. I called upon this lady to-day at her father's house in the country, and found her looking well and in all respects improved. She had recovered her proper visual power; her appetite was good; her pulse regular; her head quite clear. The only thing of which she complained was weakness in her right arm and hand, and slight numbness at the tips of the fingers; but even this seemed to be gradually getting better, and there appeared no reason why she should not also in these respects recover.

[To be continued.]

\section{HOW TO PREVENT CHLOROFORM} A C CIDENTS.*

By Charles Kidd, M.D., M.R.C.S.Eng.

Thene are few subjects at present of a more practical nature in general surgery and medicine than to ascertain the best mode of administration of chloroform, so as to avoid these melancholy and disastrous deaths that so often follow its use. As in the later treatment of pneumonia or hip.joint disease we have simplified our practice by removing certain coincidences and recognising them as coincidences, so in chloroform administration a new key has been furnished to the physiology of anæsthesia under that agent by recognising that the "cardiac syncope" of former years is a coincidence or post mortem change; and that the condition of the respiration under chloroform is far more important than the condition of the heart. It is of little advantage, or useless indeed, to strive to rouse up a flagging pulse but through the lungs and diaphragm; and we have lately found, in practice in hospitals, that this is satisfactorily effected, not by galvanism or such like to the cardiac nerves, as formerly recommerided, but by alternating ether with chloroform, which acts as a new stimulus of some kind to the air-cells of the lungs, and to the curiously complex nerves of the larynx, which are associated with the phrenic and with the diaphragm.

There is much confusion existing in our standard books as to the nature of accidents from chloroform; more particularly, too, as to the contraindications to chloroform. This has been a work of time to correct, as they were at first imperfectly guessed at as belonging to disease of heart. Most unnecessary and damaging coroners' inquests have been held on bodies, on the assumption that a mere post mortem result in the heart should have been during life anticipated by the surgeon, when probably a simple emotion of the mind (fright or nervousness), causing simple syncope, led to the accident, without a trace of cardiac disease.

\section{SYXCOPE.}

Foremost of the real contraindications, I think, is the nervous exhaustion which attends loss of food or delirium tremens. Here the patient, as in puerperal mania, should at least not have chloroform, except he shall have first obtained some natural sleep, with renewal of nervous energy in those parts of the nervous system connected with reflex and respiratory actions. 'Thus on a field of battle, as in America lately, one sees accidents from neglect of this.

Hysteric patients, or those subject to fainting fits, require great attention; and for opposite reasons. In hysteric patients, there is excess of irregular morbid nervous action, which requires a large quantity of chloroform, sometimes many ounces, to overcome it; but in patients subject to fainting fits, a few drops of chloroform may produce similar results. This form of exhaustion is not easy to describe, as it cannot be traced to the usual shock of enormous operations like ovariotomy, amputation of the thigh, etc.; for in these the law of tolerance is very marked. The state which comes perbaps nearest to it is the exhaustion of delirium tremens. This form of nervous debility, or cardiac apncea, has been very correctly described by Dr. Richardson. We have, I think, to be cautious if the patient have at any time complained of a sense of sinking or exhaustion, pallor, sleeplessness, unsteadiness of faculties ; or, if there have been a creeping, rising sensation, commencing about the heart. 'These, however, have nothing to do with Snow's cardiac syncope, which is another name for asphyxia. A very soft or intermittent pulse is always suspicious in these cases, or much spasm of the mus-

* This paper was sent to the Association meeting in London, but not read in extenso for want of time. 
cular system, or what we have just mentioned; but the death is by simple syncope. In simple syncope under chlcroform, there is no difficulty of respiration; the face is pallid; but, if we compress the cavæ, the muscles of the systemic circuit become rapidly convulsed. There is also a remarkable teudency to syncope in some persons. Thus Dr. Walshe mentions that in six patients he had met with an idiosyncrasy of this nature, though the heart was perfectly healthy. A crushed finger or a simple emotion also may each produce syncope, without chloroform at all.

\section{APNEA OR ASPHYXIA.}

The nature of accidents from chloroform begins to assume a serious practical importance and interest, not anticipated a few years ago. If an action at law for malpraxis were founded on a coroner's inquest in a case of croup, on the fact that the surgeon had not treated heart-disease, which killed a child in form of polypus or clot in the heart, we should think it very hard; or were a similar action commenced in a case of death by fever, because static pneumonia or static congestion, which takes place after death, had not been mentioned in the treatment, this would be also very absurd; but still we see something like this constantly in accidents from chloroform; and, in a recent memorable case, a condi. tion of heart as purely post mortem as the static congestion of the dead-house, and as purely accidental as the clot in the heart in the agony of dying in croup, was sought to be made the ground of malpraxis and an adverse verdict, and this view was strongly supported in medical journals.

The right side of the heart is invariably filled almost to bursting in accidents from chloroform. Where we have apnoa or asphyxia as the cause, it arises from blood mechanically pushed back by the large veins into this side of the heart during the manipulations of the dead body under the various "resuscitation methods"; it will occur, though the pulse has been quite good up to the last. But a coroner's jury found that the pulse comes from this right side of the heart; and that such heart-disease ought to have been detected before the chloroform was administered; and that such malpraxis was highly censurable!

If the pulse at the wrist comes from the right ventricle, as held by these authorities, and held very firmly, this condition of the heart may be hereafter anticipated; but I would beg of the profession to believe me when I say that this state of the right ventricle is accidental, or always to be feared where the respiration of the patient, from any cause, becomes enfeebled under chloroform. The pulse here is entirely a negative indication; and diseased heart, as a cause of death, as far as we have been able to make out from two hundred deaths from anæsthetics, is a piece of pure imagination; and, like the superiority of the Marshall Hall "ready method" for these accidents, we cannot hold these views any longer.

It occurs every week that a patient requires chloroform for some very sericus great operation, such as am. putation of the thigh, resection of knee, ovariotomy, etc. 'This patient has what one would call a "wretched" pulse-feeble, so as to be almost imperceptible; quick, faltering, or intermittent, in its beats. The doctrine of coroners' juries is, that such a patient is unfit for chloroform; that an retion for malpraxis will lie, if any accident occur, or if the Marshall Hall "ready method" have not been tried efficiently, as copied by coroners (as I have known them to do it) out of manuals or books. But it is all erroneous. This feeble pulse becomes an excellent, good pulse, under the anæsthetic.

There is much confusion existing in our standard works as to the terms asphyxia, syncope, cardiac syncope, etc., which we would wish bere to correct. The manner or mode of death in accidents from chloroform, as now described so often in hospitals and elsewhere, is evidently not alike in all cases. The ratio of asphyxie (apnœa) cases to those from simple syncope is given a9 60 to 40 , from some early examination of the returns by me; and this was further corroborated by Dr. Snow, who: stated or admitted about $20(19)$ out of 45 of his cardia syncope list exhibited signs also of what we now know to be respiratory apnœa. From no inconsiderable hos pital experience, J early entertained an impression that one form of the accident was not essentially cardiac, $a \overline{\bar{\theta}}$ held by Snow, but had its origin in some implication of the glosso-pharyngeal nerve and lungs with other vitas parts or part. This evaded observers for a timeg but now it is decided to be the diaphragm, through a branch of the eighth pair, distributed to the mucous membrane of the larynx. It is from this point the besoin de respirer, in fact, has its origin; and hence the right side of the heart is congested (cardiac syncoped only as a consequence of this spasm of the glottis an stoppage of the diaphragm, with obstruction of the bloo through the pulmonary artery.

These distinctions are of the highest clinical or prace tical importance; for, in place of directly exciting the heart, under the older doctrine of "cardiac syncope", te is found, in numerous experiments on the lower animals that this does not succeed; but by artificial respiration and Faradisation of the phrenic nerve and respirator muscles, the heart is excited, which may save man lives. An acupuncture needle should, in fact, be at onces stuck, not into the heart, but into the neck (where the omo-hyoid muscle lies at the outer edge of the sternot mastoid), so as to hit off the phrenic nerve and the other pole or needle into the floating ribs and dia phragm; or one pole into the trapezius, as described; of the simple moist pole of the induction current even into the nostril, or simply over the locality of the phrenieg and (motory) cardiac nerves about the neck and axflas If the surgeon will take along with him (in whi have explained) that the cardiac syncope of Dr. Smo and the leading surgical books is not syncope at all, $\mathbb{P}_{\text {u }}$ rather the opposite, or a form of distension from fulf action of the heart (the lungs not receiving the blood) if he will take along with him that this cardiac syncopos is rather a form of asphyxia, but which we propose to name muscular apnca, - then he will be in a bette position to understand what really takes place.

'This is a field quite unexplored-the lapse of time that may occur in suspended animation under chlor form. It is curious that, in animals drowned in wate the evil results chiefly from the plunging or struggling of the animuls; but, coteris paribus, an animal we under chloroform, and thrown into water, is not des stroyed for a much longer period. The plunging in the former instance fills the lung-tissue with water, and reु animation is very difficult after six or eight minutes but under chloroform probably a state of partial hyberna tion is established, and efforts for reanimation should be continued for four hours at least in all hospital cases. PECULIARITIES OF VARIOUS CASES : TETANUS : LITHOTOMYTO
CATARACT: NERVOUS PATIENTS : ETC.

The condition of the diaphragm in suspended anim tion from chloroform, as already said, is particulary important. Galvanism through the phrenic nerve most essential. A needle should be passed also, as ju said, through the diaphragm, as punctures of this muscloo will restore animais apparently dead from apnœ The "Silvester method" of raising the arms, so as to make the pectoral muscles and their indigitations to lie the ribs, is the best plan yet known of promoting arti ficial respiration. By this method, as much as forty four to fifty cubic inches of air (sufficient, perhaps, for ordinary breathing) pass through the chest; but in the more popular or "ready" methods, about ten. I haves urged this point for many years, but it has been disro garded. 
There are certain phenomena connected with chloroform, as regards particular operations, deserving of notice. Thus there is less bleeding now at operations than formerly, but more danger or risk of secondary hæmorrhage; as the jet of blood is diminished in force during narcotism, but when reaction sets in, the bleeding is renewed. Of the operation for vesico-vaginal fistula, we have had the opportunity, in the practice of one surgeon, of studying the greater number of fifty cases out of twice as many operations for this disease-chloroform given in all; but it was found that possibly the neces. sary large doses of opium (four or six grains in twenty. four hours) had a tendency to produce uræmia and pro. bably convulsions, which might unguardedly be aseribed to the chloroform. If such a woman be suckling, the chloroform, too, will affect the milk for a day or two after the operation; but nervous symptoms, such as fainting fits from loss of blood and pain, are now not so common after operations as in former years. "Shock", in other words, is lessencd. We have already described the use of chloroform in hernia, hip-joint diseases, obstetrics, dislocations, etc.

The decided usefulness of chloroform in tetanus is another of the very admirable new facts in connexion with this agent, as well as the opportune suggestion, when the patient's jaw is locked, to inject coneine subcutaneously. (See twenty-two cases thus cured, Medical Times and Gazette, 1861.) Nor must we look on these cases as coincidences, like pneumonia or rheumatism cured by remedies probably coincidences. Chloroform in tetanus acts rather as an auxiliary; but an auxiliary of the most vital importance.

We must remember, however, that black blood (venous) is the proper stimulus of the lungs or air-cells. Black blood circulating in the muscles causes them to contract convulsively, however, or more strongly than red blood. This will explain, perhaps, some of the phenomena of the early stages of anæsthesia. This convulsive action is very marked if in the administration the patient cease to breathe freely, or the chloroform be too concentrated. Even a fresh charge of strong sharp chloroform to the instrument is followed by fresh or temporary convulsive action from the same cause. Excite. ment, too, is greater under ether than under chloroform, with marked increase of venous congestion under the former.

The limiting line between sleep and anæsthesia comes next under notice, as well as the nature of sleep itself. All this is very important, particularly in obstetric practice. In anæsthesia from chloroform, reflex action is for a time abolisbed; but not in sleep. A patient asleep will wake up by the irritation of chloroform to become anæsthetic; and, vice versá, patients in the agony of childbirth, that have not slept for twelve hours perhaps, will fall fast asleep at the first "whitf" of chloroform, due to their release from pain. The popular idea, that anæsthesia is sleep, is not correct. Sleep, no doubt, affects chiefly the symmetrical organs, or those intermittent or periodic in their action; which chloroform also does organs endowed with only a limited amount of sensation. Chloroform, however, goes farther, and evidently engages the spinal or reflex system completely, and brings us nearer to that very serious state where all vital action ceases.

As a general rule in lithotomy, operations for calculus are now more successful than before the discovery of chloroform. The stones are now smaller than in former years, as the patient does not put off the operation till too late, and till the kidneys and bladder shall have become incurably diseased, as occurred not unfrequently in the years before this discovery. The emotion or shock, as regards the patient's feelings, is not so great. Again, in cataract operations, if the eye be sunk in its orbit, and chloroform be withheld, it becomes very diffi cult to extract the lens; but, according to the French and German operators, this is entirely obviated in such cases by administration of chloroform. In the extraction also of foreign bodies from the eye, where the pain is sometimes quite maddening, and where formerly the foreign body could not be removed, cliloroform now proves to be beyond price, especially in the case of shrieking agonised children thus injured in this important organ.

Even in medicine, effects the most opposite have fol. lowed the exhibition of chloroform. Thus jaundice has been known to supervene on its use, probably from paralysis of the ductus choledicus; and, again, jaundice has been cured by chloroform where a gall-stone was obstructing this same canal, with pain and spasm. The number of objects for which chloroform is now administered is very great: reduction of dislocations; "putting up" bad fractures ; passing instruments in all but impervious strictures; sounding for stone; application of cautery; etc. It is perhaps in cases of "turning" in obstetrics, so much facilitated by chloroform, and now superseding the forceps, that the beauty of chloroform is shown; and, if it be true in any degree that the forceps in midwifery injures the infant's brain, and leads to idiocy and lunacy in after life, what a boon chloroform must be!

The rate of mortality after all surgical operations is perhaps very little influenced by chloroforin. I have obtained very reliable statistics on both sides. At one side, as in lithotomy, the rate is lessened; but, on the other side of the account, we have amputations at the hip-joint and ovariotomy; we have also a larger number of operations of all sorts, and more chance of casualties from crowding of such patients-pyæmia, erysipelas, etc. Deaths, too, are now perhaps more carefully registered than formerly.

In fits of asthma, as also in croup, I have known the inhalation of a small quantity of ether and chloroform, mixed from a sponge squeezed ont of hot water, to act like a charm. 'Tobacco and chloroform are the two best remedies for asthma, according to the very able work of Dr. Hyde Salter on that disease.

The physician should be familiar, however, with the difference between ordinary sleep in patients which sometimes supervenes on the release from agony under chloroform, and the anæsthesia of that agent itself; as also the action of air and chloroform vapour in the lung.

If, in an animal deeply chloroformed, two nerves be laid bare-a sensory and a motory nerve-galvanisin at once excites the muscles to which the latter goes, but not the former.

The condition and bearing of the diaphragm during anæsthesin is very deserving of notice, as on this the life of our patient may in a great measure, and most probably actually does, depend. 'This "musculus nobilissimus post cor" is passive or tolerant to the slighter degree of etherisation; but it is to be feared that, in a number of fatal accidents, it stops from inhibitory action of the nerves of the mucous membrane of the larynx reflected or continued to this muscle. We know how closely connected these two parts are in coughing, if a grain of salt, etc., thus, as it is termed, "goes the wrong way"-that is, into the clink of the glottis; so of the irritation of concentrated or acid chloroform on the same part-the diaphragm then becomes fixed without coughing. This has been proved very clearly, in experiments on the lower animals, as one of the causes of death (though arrived at independently of the clinical facts). It agrees, too, with the group of phenomena as to the fatal accidents occurring more frequently at the end of the second stage; before deep anæsthesia, occurring suddenly as spasm of the glottis; before operation, too, when probably the patient, partially delirious, plunges and takes irregular, smothered, and occasionally gasping deep inhalations of the vapour. The venous system of the 301 
limbs is engorged also under this action of the muscles, pushing blood in large quantities to the overgorged right cavities of the heart.

In the lower animals, again, exposed to injuries of the sympathetic nerve as experiments, sugar collects in the blood; and here it is found in such diabetics that the smallest possible quantity of chloroform now given kills the animal, though previously to section of the sympathetic, the animals would bear the anæsthetic very well. This, of course, is not a state likely to be met in the human subject; it is still, however, very suggestive, reminding us to be careful of chloroform in cases of deep exhaustion, or where cancerous, or such disease, may in. terfere with large nerves, or where the reflex system is deficient from any cause.

It is advisable, where we have reason to fear simple syncope, as in very " nervous" patients, or in an accident suddenly requiring surgical treatment in a drunken patient, to postpone the operation, if at all possible, for a week; to administer in the interval bark and ammonia, with meat and wine; to fix a certain day for the operation, and do it the day before; to operate early in the day, after a night of sound sleep; and, immediately before operating, to give a claret-glass of wine, with twenty drops of spirits of ammonia in it, which I now prefer to brandy. Such a patient may even go through the chloroform and operation very well, and faint sub. sequently, if allowed to walk about too soon; but this is not dangerous. Hospital experience has taught us that, in cases of impending death, the heart contracts longer than the pupil of the eye; so that the latter may be appealed to with advantage in all these cases of syncope, and the heart roused to action but through the lungs.

Some patients, again, are constitutionally subject to syncope ; a fact that should never be lost sight of. Thus, Heurteloup has seen very alarming syncope from simply touching the interior of the urethra. Then, again, injuries of thecal canals, tendons, etc., may also produce dangerous fainting. Patients labouring under, or with a tendency to diabetes, there is reason to fear are also subject to sudden syncope and death from chloroform. Mr. Syme also mentions facts like those of Heurteloup.

[To be continued.]

\section{Transactions of âdanthes.}

\author{
R E A D I N G B R A N C H. \\ PRESIDENT'S ADDRESS. \\ By Edward Wells, M.D., F.R.C.P., Reading. \\ [Delivered July 16th, 1802.]
}

Gentlemen,-While the reporter of the proceedings of your Pathological Society brings before you the present state of the science of medicine and surgery, to illustrate the history of the cases which have come before you during the past year, it would seem to be the duty of him, who occupies the post which by your kindness I have the honour to fill, to direct your attention to the general polity of medicine as a profession. I shall endeavour, therefore, in my address to-day, to give you a brief summary of such circumstances as have occurred since we last met, which may appear to have exercised a control, for good or for ill, over the fortunes of that host in whose ranks we have enroiled ourselves.

The very fact that I am called upon to address you at all, the mere coming together of yourselves into this room on this occasion, is a direct proof that as medical men we have a corporate existence, that we have collective interests, that we have reciprocal duties towards one another. Our paths of duty may be separate; they may be so narrow as to allow but one passenger at a time;

302 still they should all run in one direction, and all follow the guiding of one compass. Like planets, we may revolv in different orbits, but we should all keep true to or centre. We should endeavour to make the profession something more than an abstract idea, to give it a visible and corporeal existence, to recognise its claims upon ou selves, while we endeavour to obtain respect for it from society at large.

It is, I presume, with this idea that our Association has been formed; it is with this object that it sends forth its Branches over the length and breadth of the land and that we, as representing one of those Branches, have met here to-day.

Let us hope that the meeting of our Association this year in the great metropolis, assembling in the ancient halls of the College of Physicians, under the presideney of an eminent London physician, may tend still further to develope this idea, and to rally round us those who have hitherto stood aloof from us, not from any hostility but rather because they have failed to realise and feet that esprit de corps which should animate the members of every profession.

In one important item, viz., in its means of commun? cation with the external world, I think we must all agree that the Association has made of late considerable inso provement. The British Medical Journal is now 9 real gain to our members, and amply repays the outlay their subscription. Some fault has been found with ow editor, because he discusses ex cathedra certain contros versial subjects, and, as it were, pronounces judgment be tween the rival theorists. It has been said that be ho no right to enunciate in an editorial article his own private opinions, as if they were the dicta of the British Medica Association. I cannot myself participate in these obje tions; for I believe that no one is;deluded into regarding these remarks as anything more than the private vien of one individual. And if answers to them are fairloba mitted into the Journal, from those who may im the conclusions at which he has arrived, no injusticeram ensue. On the contrary, they have the advantage bringing before us many interesting questions, and challenging discussion upon them.

We must, I think, all approve the manly tone in whic the Journal has combated the fashionable humbugs of the day. In those more delicate matters which concer the ethical relations existing between individual menf bers, its sentiments have, I believe, met with genera approval; and its whole conduct during the past yea may be said to have promoted the advancement of the Association.

The Medical Council has already cost the members the profession $£ 40,000$ and upwards. Of this sun $£: 3 \pm, 000$ have been extracted from the pockets of pre viously qualified practitioners, who little dreamt of bein called upon to pay for an additional license to practise. has been paid without grumbling; for the profession fed the need of a ruling body, who could at the same time an organ of communication with the Government.

The Council is armed with the power of inflicting penalties. As the Red Indian parades his scalps, ting trophies of his achievements, the Council will, no doub by the number of penalties inflicted, prove to the profes sion its watchfulness in guarding their rights. Hithert their exploits in this direction have not been very successo ful. The single penalty is $£ 2()$. In the year 1859 , th penalties imposed produced $£ 24$; in $1860, \mathfrak{E} 14: 10$; i $1861, \pm 5: 1: 3$. In the estimated income for $1862, \mathrm{I}$ ofer serve no penalties at all are calculated upon, although the Council is rather short of cash.

The Medical Act itself is, however, partly to be blameg for the impunity with which impostors still pretend to be recognised by law as duly qualified practitioners. It would appear as easy to drive a coach and six througd the Medical Act, as through any other Act of Parliamenक And probably the Medical Council will feel little en? 